\title{
EDITORIAL
}

\section{Publishing collaborative studies between academics and industry}

\author{
P.J. Sterk*, K. Larsson**, R. Naeije+, U. Costabel++
}

\section{Research partnership}

During the last decade we have observed a large progress in biomedical research in general, and in the pulmonary field in particular. This is shown by the almost exponential increase in the quantity of published science, as well as by the obvious improvement of its overall quality. We are very pleased that this is certainly apparent from the current submissions to the European Respiratory Journal (ERJ).

Presumably, one of the reasons for this favourable development is the improved exchange of information among scientists all over the world. This has been facilitated by modern communication techniques, and seems to have led to intensive and frank collaboration between different research groups and institutes. It has become evident that scientific achievements can no longer be made by a single department or laboratory very easily, and that strategic partnerships are usually required for solving today's research questions.

A major example of such a successful partnership is the apparent increase in collaborative studies of scientists from universities or hospitals with those from commercial institutes, such as the pharmaceutical industry. Given their partially distinct focus and experimental facilities, such co-operative efforts are often highly complementary, eventually being indispensable for treatment development. In this way the partnership is beneficial to both parties, allowing an enhanced progress of innovative in vitro and in vivo biomedical research.

It cannot be ignored that in days of shrinking public resources for granting biomedical research, collaboration with the pharmaceutical industry is also of financial importance to the academic scientific community. Industrial sponsorship is increasingly mentioned in the papers submitted to e.g. the ERJ, and in the abstracts of the European Respiratory Society (ERS) and American Thoracic Society (ATS) meetings. It is obvious that in publishing such research, both partners might have partially distinct objectives, varying between barely scientific to commercial intentions.

We like to emphasize that the above developments can be regarded as favourable, provided that the mutual responsibilities in collaborative research projects have been clearly delineated in a formal contract. It is selfevident that such a contract between research partners

*Lung Function Laboratory C2-P, Leiden University Medical Centre, Leiden, The Netherlands. **Dept of Occupational Health, National Institute of Working Life, Solna, Sweden. ${ }^{+}$Dept des Soins Intensifs, Hôpital Universitaire Erasme, Bruxelles, Belgium. ${ }^{++}$Ruhrlandklinik, Abt Pneumologie/Allergologie, Essen, Germany.

Correspondence: P.J. Sterk, Lung Function Laboratory, C2-P, Leiden University Medical Centre, P.O. Box 9600, NL-2300 RC Leiden, The Netherlands. should be in accordance with legal and ethical regulations, and with the standard rules generally obeyed by the scientific community.

\section{What can go wrong?}

The editors of the ERJ have recently faced a serious dilemma as to whether to publish a manuscript submitted by PALMQvist et al. [1]. This is a collaborative study between academic researchers and a pharmaceutical company. Although not innovative in the strict sense, the study provides useful data on the application of antiasthma drugs, also to be used for an international registration dossier. Even though the manuscript of the study had passed the scientific peer review process after revision based on the comments from the reviewers and the editor of the $E R J$, to our surprise it subsequently became evident that major parts of the data, including three figures, had already been published previously in a review article (a so-called "Clinical Expert Report") of a national, non-peer review newsletter of one of the countries in Europe. This led to our decision to reject the paper for publication in the ERJ, which according to the instructions to authors excludes acceptance of manuscripts that include data previously published in another journal.

After informing the principle investigator and the first author of our decision to reject the ERJ manuscript, it appeared that the previous article including the data had been written - under the auspices of the company - by an author who was not involved in the actual study, without informing the principle investigator or his colleagues. We consider this an inconceivable incident, being suggestive of an independent publishing policy by the sponsoring partner of the study. It may also point towards inadequate arrangements between the investigators and the company on their rights and duties in the contract in question. Following correspondence between the Editor of the ERJ, the principle investigator, and the sponsor, the latter expressed its apologies and quickly decided to stop the distribution of the national newsletter and to destroy all remaining copies.

In order to be fair to the first author and the principle investigator of the study, and to allow publication of the data after peer review as mentioned above, we have eventually repealed our decision to reject the ERJ manuscript. The present editorial serves to justify the publication of the paper by PALMQVIST et al. [1] in the present issue of the ERJ.

\section{Publishing the data}

We believe that the above incident should serve to clarify the responsibilities among the respiratory academia 
and the pharmaceutical industry in publishing collaborative research studies. Again, these must be outlined in the contract between the partners based on legal and ethical regulation, and on the common rules respected by the scientific community.

From an editorial point of view, we wish to provide the following guidance for drawing up such contracts between academic researchers and their partner from a sponsoring company with regard to publication of the data:

1) Publishing rights. The right and decision to publish the study data in a peer review scientific journal is restricted to the principle investigator of the study only. Hence, if the principle investigator is a researcher working in academia, this right and decision is not dependent on permission by the sponsor. However, the sponsor must receive a copy of the manuscript prior to submission, enabling the company to give comments and criticism. This can delay the submission of the manuscript for a maximum of a predetermined negotiable period. After that period, the principle investigator will be allowed to publish the data in a peer review scientific journal. Of course, each research partner should be mentioned in the manuscript, whilst each of the co-authors shares the responsibility for the data submitted.

2) Double publication. Even though the so-called "Ingelfinger rule" (named by a former editor of the New England Journal of Medicine) [2] on (partial) double publication has been criticized [3,4], the ERJ adopts this rule when publishing scientific manuscripts. This rule is still applied by the world's leading biomedical journals, and implies that earlier publication of the same data elsewhere precludes subsequent publication in a peer review journal. Hence, the instructions to authors by the ERJ state that "neither the work nor any part of its essential substance, tables or figures has been published or will be published or submitted to another scientific journal or is being considered for publication elsewhere". We consider abstracts to scientific meetings and academic theses to be exceptions to this rule. However, it is not acceptable to pre-publish data in tables or figures based on results obtained from abstracts published prior to appearance of the peer review paper. Of course, following peer review publication, it remains possible to publish the same data elsewhere, when adequately quoting the original article. Such subsequent publication (e.g. by the other research partner in nonpeer reviewed media) is only possible after formal approval by the principle investigator and formal approval of the copyright transfer by the journal.

3) Conflicts of interest. For this we are referring to generally accepted rules [5], and to the paragraph in question in our instructions to authors. Among other things the latter states the following: "Every author of each manuscript is responsible for recognizing and disclosing financial and other conflicts of interest related to their study or to the subject of their review or editorial article. The authors have to acknowledge in a manuscript all financial support for the work and other financial or personal connection to the work. In case of single- or multi-centre trials with blinded intervention, the code must have been broken at the end of the study in the presence of the responsible investigator of each centre. The code and the data will then be available to each participating centre. The first author makes provisions that, if needed, the code and the data are available to the ERJ for independent statistical analysis".

Hence, we consider it to be essential that the study code and the data can be checked and re-analysed by each of the investigators of the study, and in exceptional cases, also independently by the editors of the publishing journal.

\section{Peer review}

In view of the above the editors of the $E R J$ wish to underline the critical role of the peer review system when publishing the results of scientific studies. This procedure aims to yield an independent quality control of submitted manuscripts by anonymous scientists in the research field of interest (peers), selected by the editor of the journal. Such peer review processes can either lead to rejection of the paper for publication, or to acceptance provided that, if necessary, revisions are being made consistent with the comments and questions by the reviewers.

Obviously, the peer review system is not fullproof, and certainly not a fool-proof quality check. It has several implicit limitations, such as its subjective character. Therefore this procedure may bias and certainly delay the flow of scientific news to the public $[3,4]$. Hence, we have to admit that editors cannot guarantee the validity of the data published. However, we consider the peer review system as still being the best, currently available safety valve in the presentation of results obtained by scientist to the media. The importance of this cannot be emphasized enough during these days of explosive developments in the rapid, but uncontrolled worldwide communication through electronic techniques, including the internet. This can easily promote the distribution of scientific misinformation, which should be limited by peer review.

\section{Conclusion}

We hope that the above provides a balanced and appropriate justification of the publishing policy of the $E R J$ in general, and the publication of the manuscript by PALMQVist et al. [1] in the present issue of the journal in particular. We have used the latter paper as an occasion to highlight the desirable procedures when publishing scientific data.

We are convinced that the majority of collaborative studies between academia and industry are being conducted according to the above conditions. This mode of respectful collaboration is certainly one of the major reasons for the obvious progress in today's biomedical research.

\section{References}

1. Palmqvist M, Persson G, Lazer L, Rosenborg J, Larsson $\mathrm{P}$, Lötvall J. Inhaled dry-powder formoterol and salmeterol in asthmatic patients. Eur Respir J 1997; 10: 24842489.

2. Relman AS. The Ingelfinger rule. N Engl J Med 1981; 305: 824-826.

3. Altman LK. The Ingelfinger rule, embargoes, and journal peer review. Lancet 1996; 347: part 1: 1382-1386.

4. Altman LK. The Ingelfinger rule, embargoes, and journal peer review. Lancet 1996; 347: part 2: 1459-1463.

5. International Committee of Medical Journal Editors. Conflict of interest. Lancet 1993; 341: 742-743. 